\title{
Individual variations in the vascular content of retrodiscal tissue in the temporomandibular joint: a study using histological sections of human foetuses and magnetic resonance images of adults without pathology
}

\author{
M. Yamamoto ${ }^{1}$, K.H. Cho ${ }^{2}$, S.S. Choi ${ }^{3}$, J.F. Rodríguez-Vázquez ${ }^{4}$, G. Murakami ${ }^{5}$, S. Abe ${ }^{6}$ \\ ${ }^{1}$ Department of Anatomy, Tokyo Dental College, Chiba, Japan \\ ${ }^{2}$ Department of Neurology, Wonkwang University School of Medicine, Iksan, Republic of Korea \\ ${ }^{3}$ Department of Radiology, Wonkwang University School of Medicine, Iksan, Republic of Korea \\ ${ }^{4}$ Department of Anatomy and Embryology II, Faculty of Medicine, Complutense University, Madrid, Spain \\ ${ }^{5}$ Division of Internal Medicine, Iwamizawa Kojin-kai Hospital, Iwamizawa, Japan \\ ${ }^{6}$ Department of Anatomy, Tokyo Dental College, Chiba, Japan
}

[Received 25 October 2013; Accepted 8 December 2013]

\begin{abstract}
The vascular content of retrodiscal tissue in the temporomandibular joint (TMJ) plays a critical role in joint function, and its morphology is therefore likely related to TMJ pain. Using histological sections of human foetuses as well as T2-weighted magnetic resonance images $(M R I)$, we measured the vascular content of retrodiscal tissue. MRI showing no pathology in and around the TMJ were obtained from 18 young patients who had been suffering from headache. In 10 small foetuses (12-14 weeks of gestation) as well as 10 larger foetuses (30-37 weeks), the vascular content showed individual variations exceeding 5 times the minimum value $\left(0.24\right.$ vs. $0.04 \mathrm{~mm}^{2}$ per $1 \mathrm{~mm}^{2}$ ), but no difference between foetal stages was evident. In the MRI from young adults, the variation was less than twice the minimum value (13.6 vs. $8.7 \mathrm{~mm}^{2}$ per $100 \mathrm{~mm}^{2}$ ). The vascular density appeared to be lower in adults than in foetuses. In both foetuses and adults, the thickness (anteroposterior length) of the tissue did not correlate with the vascular sectional area. These findings suggest that the considerable inter-individual differences evident in the vascular content of foetal retrodiscal tissue may be reduced during further development. (Folia Morphol 2014; 73; 2: 153-158)
\end{abstract}

Key words: temporomandibular joint, retrodiscal tissue, human foetus, vascular content, individual differences, adult magnetic resonance imaging

\section{INTRODUCTION}

Retrodiscal tissue of the temporomandibular joint (TMJ) consists mainly of loose connective tissue, composed of elastin and collagen fibres, and an extensive venous plexus in the deeper layers $[21,26]$, with these veins differing from the pterygoid venous plexus and the superficially located retromandibular vein. Merida-Velasco et al. [15] demonstrated abundant vessels (mostly veins) in the foetal retrodiscal tissue at 12 weeks. At this point, elastic fibres have

Address for correspondence: K.H. Cho, MD, PhD, Department of Neurology, Wonkwang University School of Medicine, Jeonbuk Regional Cardiocerebrovascular Disease Centre, Institute of Wonkwang Medical Science, 895, Muwang-ro, Iksan, Jeonbuk, 570-711, Republic of Korea, fax: 82-63-842-7379, e-mail: neurlogy@wonkwang.ac.kr, neuro20015@gmail.com 
not yet developed [11]. Thus, retrodiscal tissue contains abundant vessels before establishment of the connective tissue architecture. We recently observed considerable inter-individual differences in the vascular content of retrodiscal tissue between foetuses at the same stage $[8,9]$. This motivated us to perform the present quantitative study: the primary aim of this study was to compare the vascular content of the retrodiscal tissue between small and larger foetuses.

Despite retrodiscal tissue being a major focus of interest, no attempt has yet been made to quantitatively evaluate vessels in the retrodiscal tissue of the adult TMJ without pathology. Using elderly cadavers, Sakuma et al. [20] compared histology with T1-weighted magnetic resonance images (MRI) and concluded that the intensity of the signal did not correlate significantly with blood vessel density. Although we compared foetal histology with adult MRI, we did not utilise signal intensity but chose vessel-candidates from the MRI. The second aim of this study was to evaluate the normal vascular content of adult retrodiscal tissue using MRI.

\section{MATERIALS AND METHODS}

\section{Histological study using human foetuses}

This study was performed in accordance with the provisions of the Declaration of Helsinki 1995 (as revised in Edinburgh 2000). We examined paraffin-embedded sections of 20 foetuses. Ten of these foetuses were small (approximately 12-14 week of gestation; crown-rump length [CRL] 82-103 mm) and the other 10 were large (30-37 weeks of gestation; CRL 240-310 mm). The genders were undocumented. All specimens were part of the large collection kept at the Embryology Institute of the Universidad Complutense, Madrid, being the products of emergency abortion, miscarriages and ectopic pregnancies managed at the Department of Obstetrics of the University. The donated foetuses had been fixed in $10 \%(\mathrm{w} / \mathrm{w})$ formalin solution and stocked in the same solution for more than 3 months. After dividing the foetuses into body parts, the head specimens were decalcified in $5 \%(\mathrm{w} / \mathrm{w})$ nitric acid at room temperature for 1-3 days, depending on the size. Approval for the study was granted by the ethics committee of the Universidad Complutense. After routine procedures for paraffin-embedded histology, sections

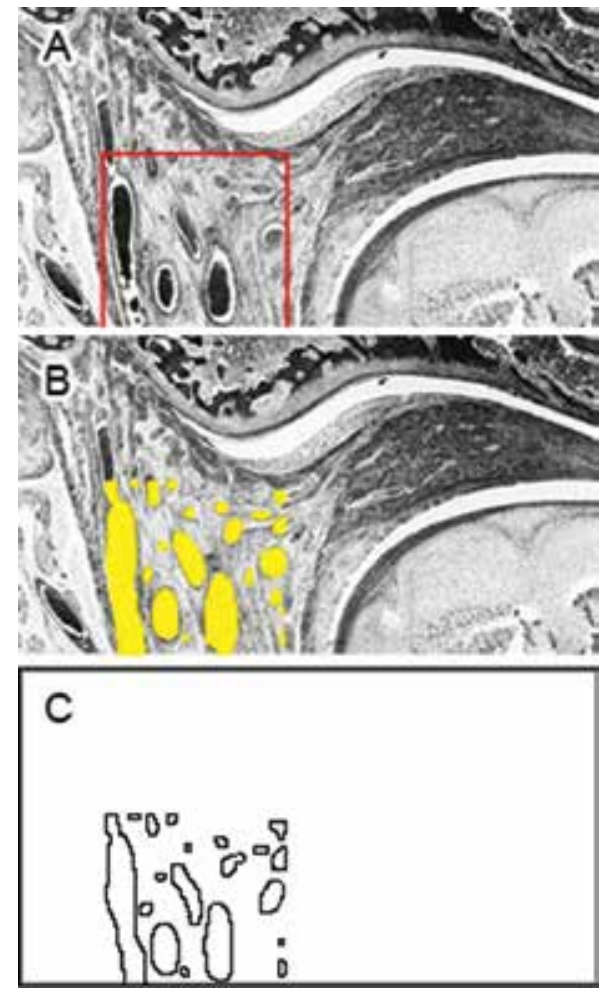

Figure 1. A, B, C. Method to evaluate vessels in the foetal retrodiscal tissue.

were cut sagittally at a thickness of 10 microns, at intervals of $0.5 \mathrm{~mm}$ (large foetuses) or 100 microns (small foetuses), and stained with haematoxylin and eosin or Masson trichrome.

Among sagittal sections that included the foetal TMJ, we chose a single section that displayed the highest density of vessels in the retrodiscal tissue (Fig. 1A). We selected the vessel candidates in the images (yellow-coloured vessel-like structures in Fig. 1B) and picked them for scanning (Fig. 1C). The scanned images (Powerpoint ${ }^{\circledR}$ images) were processed using the Image J program (developed at the U.S. National Institutes of Health and available on the internet at http://rsb.info.nih.gov/ij/). The measured area was a rectangle, $1 \times 2 \mathrm{~mm}$ in small foetuses and $2 \times 3 \mathrm{~mm}$ in large foetuses, with the upper margin ( 1 or $2 \mathrm{~mm}$ ) corresponding to a horizontal plane along the thinnest membranous portion of the joint disk. We chose the rectangle that contained the largest number of vessel candidates in that foetus. Thus, the distance from the anterior or posterior margin of the rectangle to the mandibular head varied slightly among the foetuses. 


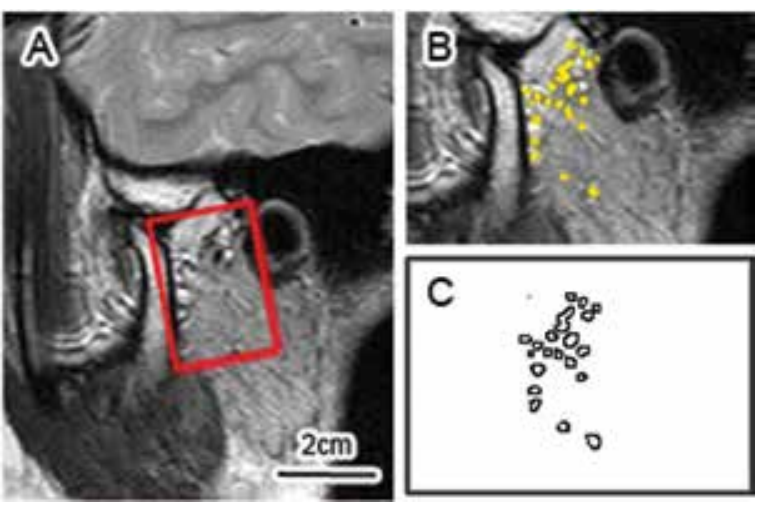

Figure 2. A, B, C. Method to evaluate vessel-candidates in adult T2-weighted magnetic resonance images.

\section{MRI analysis in young adults}

Approval for a waiver of consent for retrospective chart review studies was granted by the ethics committee of the Wonkwang University Hospital. To compare sectional areas of vessel candidates between foetal histology and adult MRI, we used T2-weighted MRI $(224 \times 224$ pixel matrix; 1.5 T, GE Medical System) taken in the open-mouth position in 18 young patients ( 8 males and 10 females, ranging in age 11-26 years) who visited the headache clinic of Wonkwang University Hospital because of temporal headache, but had no pathological findings on MRI. The names of the patients were changed to case numbers to make individual identification impossible. The slice thickness was $3 \mathrm{~mm}$ with an additional 0.3-mm gap. An experienced radiologist (SSC) confirmed that the MRI showed no evidence of pathology in the TMJ or retrodiscal area. We measured the unilateral retrodiscal areas. Similarly to measurements using foetal histological sections, the measured area in MRI was a rectangle $(20 \times 30 \mathrm{~mm})$, with the upper margin (20 $\mathrm{mm}$ ) corresponding to a line connecting the superior end of the external acoustic meatus to the upper end of the mandibular head (red lines in Fig. 2A). The distance from the anterior or posterior margin of the rectangle to the mandibular head varied between persons. From the MRI obtained from each subject, we chose the image containing the largest numbers of vessel candidates. We selected the vessel candidates in the images (yellow coloured vessel-like structures in Fig. 2B) and picked them for scanning (Fig. 2C). The scanned images were processed with the same software as used for measurement of foetal histology (see above). In addition, we measured the distance between the mandibular head and the acoustic meatus to evaluate the thickness of the retrodiscal tissue. Data were evaluated statistically using Student's t-test, $\chi^{2}$ tests and one-way analysis of variance.

\section{RESULTS}

\section{Small foetuses (histology)}

The retrodiscal tissue was composed of loose mesenchymal tissue. Plexus-like veins in the retrodiscal tissue were located near the superficial temporal artery and vein (Fig. 3A, B), but these vessels were not included in our measurements. In small foetuses, in which the measured area was $2 \mathrm{~mm}^{2}$, the largest and smallest vascular areas were $0.22 \mathrm{~mm}^{2}$ per $1 \mathrm{~mm}^{2}$ and $0.04 \mathrm{~mm}^{2}$ per $1 \mathrm{~mm}^{2}$, respectively (mean, $0.15 \mathrm{~mm}^{2}$ per $1 \mathrm{~mm}^{2}$; Table 1). Thus, the range of areas was over 5 -fold. The distance between the mandibular head and the acoustic meatus (a parameter of retrodiscal tissue thickness) ranged from $0.8 \mathrm{~mm}$ to $1.5 \mathrm{~mm}$. However, there was no correlation between the distance and the sectional vascular area $(r=0.084)$.

\section{Large foetuses (histology)}

The foetal retrodiscal tissue was fibrous but did not have a bilaminar structure, in contrast with that in adults [10]. The venous plexus in the retrodiscal tissue was distant from the superficial temporal artery and vein (inferior to and outside Fig. 3C, D). In large foetuses, in which the measured area was $6 \mathrm{~mm}^{2}$, the largest and smallest vascular areas were $0.24 \mathrm{~mm}^{2}$ per $1 \mathrm{~mm}^{2}$ and $0.04 \mathrm{~mm}^{2}$ per $1 \mathrm{~mm}^{2}$, respectively (mean $0.16 \mathrm{~mm}^{2}$ per $1 \mathrm{~mm}^{2}$; Table 1). Thus, similar to the small foetuses, the range of areas was over 5-fold. The distance between the mandibular head and the acoustic meatus ranged from $2.2 \mathrm{~mm}$ to $4.5 \mathrm{~mm}$, but there was no correlation between tissue thickness and sectional vascular area $(r=0.075)$.

\section{Young adults (MRI)}

The retrodiscal tissue was identified as a highintensity area between the external acoustic meatus and the mandibular ramus, but the laminar architecture seen in adults [10] was unclear. In MRI of young adults, in which the measured area was $600 \mathrm{~mm}^{2}$, the largest and smallest vascular areas were $13.6 \mathrm{~mm}^{2}$ per $100 \mathrm{~mm}^{2}$ and $8.7 \mathrm{~mm}^{2}$ per $100 \mathrm{~mm}^{2}$, respectively (mean $11.4 \mathrm{~mm}^{2}$ per $100 \mathrm{~mm}^{2}$; Table 2, Fig. 4). Thus, the inter-individual variation was less than 2 -fold. The mean areas in males and females were similar (11.6 

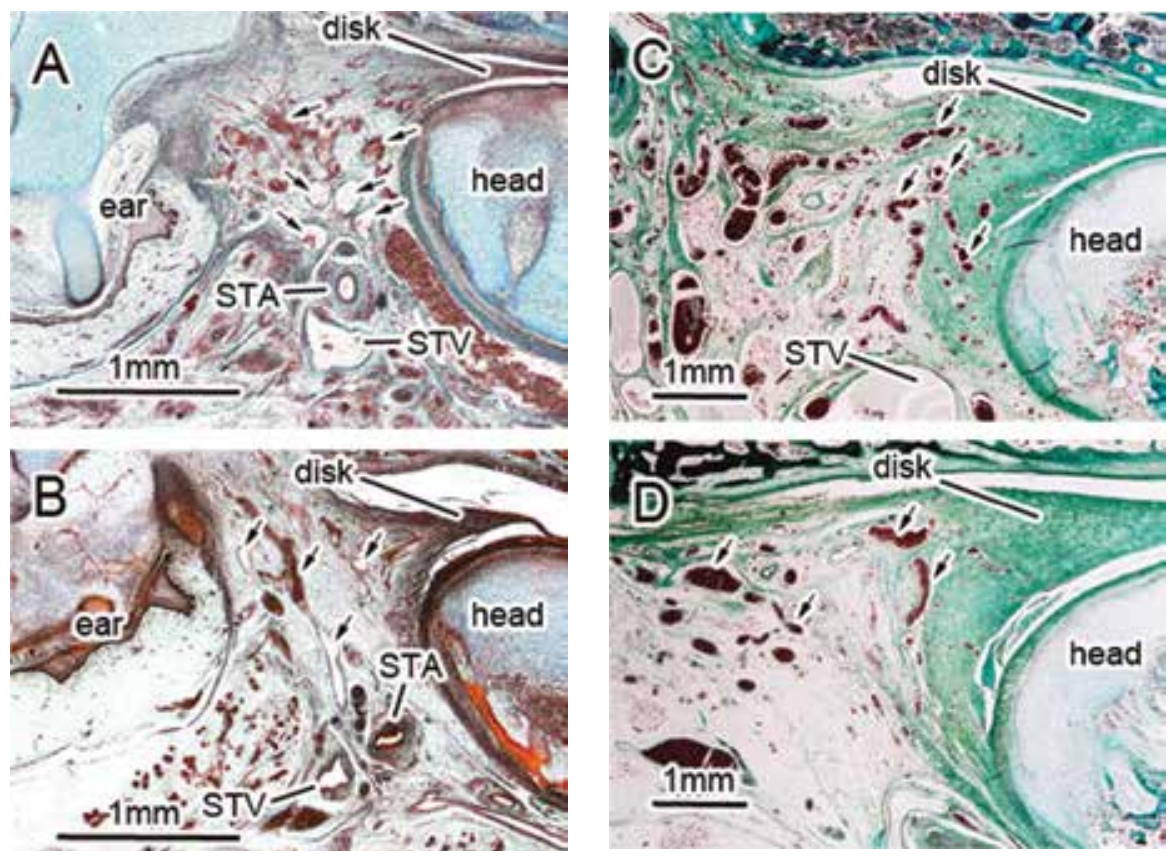

Figure 3. Individual variation in amount of vessels in the foetal retrodiscal tissue: sagittal section histology; Panels A, B (haematoxylin and eosin staining) display the small foetuses, while panels C, D (Masson-trichrom staining) the large foetuses. The left-hand side of the figure corresponds to the posterior side of the head. Arrows indicate veins in the foetal retrodiscal tissue. Panel A (12 weeks of gestation; crown-rump length [CRL] $86 \mathrm{~mm}$ ) exhibits the moderate amount of vessels $\left(0.15 \mathrm{~mm}^{2}\right.$ per $\left.1 \mathrm{~mm}^{2}\right)$ in contrast to panel $\mathbf{B}(14$ weeks; $100 \mathrm{~mm} \mathrm{CRL})$ with the second lowest amount $\left(0.09 \mathrm{~mm}^{2}\right.$ per $\left.1 \mathrm{~mm}^{2}\right)$. Likewise, panel C (32 weeks of gestation; $270 \mathrm{~mm} \mathrm{CRL)} \mathrm{shows} \mathrm{the} \mathrm{moderate} \mathrm{amount} \mathrm{of} \mathrm{ves-}$ sels $\left(0.13 \mathrm{~mm}^{2}\right.$ per $\left.1 \mathrm{~mm}^{2}\right)$ in contrast to panel D (35 weeks; $290 \mathrm{~mm}$ CRL) with the third lowest amount $\left(0.04 \mathrm{~mm}^{2}\right.$ per $\left.1 \mathrm{~mm}^{2}\right)$. Panels A, B (C, D) are prepared at the same magnification; head — mandibular head; STA — superficial temporal artery; STV — superficial temporal vein.

Table 1. Measured sectional area of vessels in the foetal retrodiscal tissue ( $\mathrm{mm}^{2}$ per $1 \mathrm{~mm}^{2}$ of the tissue)

\begin{tabular}{lccccccccccc}
\hline Small foetuses & 0.04 & 0.09 & 0.12 & 0.13 & 0.15 & 0.15 & 0.15 & 0.18 & 0.20 & 0.22 & $0.15 \pm 0.05^{*}$ \\
[weeks] & 12 & 14 & 14 & 12 & 12 & 14 & 13 & 14 & 12 & 13 & \\
Large foetuses & 0.04 & 0.07 & 0.11 & 0.13 & 0.15 & 0.16 & 0.19 & 0.20 & 0.21 & 0.24 & $0.16 \pm 0.06^{*}$ \\
[weeks] & 35 & 32 & 33 & 32 & 37 & 35 & 30 & 37 & 33 & 33 & \\
\hline
\end{tabular}

*Mean \pm standard deviation

vs. $11.3 \mathrm{~mm}^{2}$ per $100 \mathrm{~mm}^{2}$ ). Following normalisation, the data in adults were almost the same as or slightly smaller than those in foetuses, suggesting that vascular density was decreased in adults despite adult data being likely to include the superficial temporal vein. The distance between the mandibular ramus and the acoustic meatus in young adults ranged from $15.8 \mathrm{~mm}$ to $24.5 \mathrm{~mm}$ (mean $21.7 \mathrm{~mm}$ ). Although, again, the thickness of the retrodiscal tissue varied among individuals, distance was not correlated with sectional vascular area $(r=0.081)$.

\section{DISCUSSION}

Previous studies of the foetal TMJ disk have concentrated on its connections with the middle ear $[1,15,18,19]$, and the lateral pterygoid muscle $[3,5$,
16, 23]. Harada and Ishizeki [4] described connective tissue formation after degeneration of Meckel's cartilage. Does the development of retrodiscal vessels relate to degeneration of Meckel's cartilage? The rich content of vessels is unlikely to be a remnant of Meckel's cartilage because, at 12 weeks (the same as in the present small foetuses), Merida-Velasco et al. [15] showed that all parts of the cartilage were associated with vessel-rich retrodiscal tissue. Despite the maturation and increased content of connective tissue fibres in the larger specimens, vascular density was almost identical in larger and small foetuses. In small foetuses, the lateral pterygoid muscle was already inserted into the disk [3, 5, 16, 23]. We found that the vascular content of foetal retrodiscal tissue varied significantly among specimens, in con- 
Table 2. Measurement of vessel-candidates in MRI

\begin{tabular}{|c|c|c|c|c|}
\hline \multirow[t]{2}{*}{ Patient no. } & \multirow{2}{*}{$\begin{array}{c}\text { Age } \\
\text { and } \\
\text { gender }\end{array}$} & \multicolumn{2}{|c|}{ Vascular area } & \multirow{2}{*}{$\begin{array}{c}\text { Max } \\
\text { thickness } \\
{[\mathrm{mm}]^{* *}}\end{array}$} \\
\hline & & $\begin{array}{l}\mathrm{mm}^{2} \\
\text { total* }\end{array}$ & $\begin{array}{l}\mathrm{mm}^{2} \text { per } \\
100 \mathrm{~mm}^{2}\end{array}$ & \\
\hline 1 & $18 \mathrm{M}$ & 52.0 & 8.7 & 22.8 \\
\hline 2 & $23 \mathrm{~F}$ & 63.4 & 10.6 & 15.8 \\
\hline 3 & $16 \mathrm{~F}$ & 61.3 & 10.2 & 21.6 \\
\hline 4 & $18 \mathrm{~F}$ & 67.8 & 11.3 & 24.5 \\
\hline 5 & $20 \mathrm{~F}$ & 56.0 & 9.3 & 24.5 \\
\hline 6 & $21 \mathrm{~F}$ & 81.4 & 13.6 & 21.2 \\
\hline 7 & $22 \mathrm{M}$ & 77.1 & 12.9 & 23.8 \\
\hline 8 & $21 \mathrm{M}$ & 75.6 & 12.6 & 22.8 \\
\hline 9 & $21 \mathrm{M}$ & 63.6 & 10.6 & 17.5 \\
\hline 10 & $26 \mathrm{~F}$ & 67.7 & 11.3 & 24.5 \\
\hline 11 & $25 \mathrm{~F}$ & 56.5 & 9.4 & 21.9 \\
\hline 12 & $12 \mathrm{M}$ & 69.4 & 11.6 & 18.4 \\
\hline 13 & $16 \mathrm{M}$ & 74.8 & 12.5 & 23.0 \\
\hline 14 & $24 \mathrm{~F}$ & 72.4 & 12.1 & 22.3 \\
\hline 15 & $11 \mathrm{~F}$ & 71.8 & 12.0 & 21.6 \\
\hline 16 & $13 \mathrm{~F}$ & 79.2 & 13.2 & 21.7 \\
\hline 17 & $24 \mathrm{M}$ & 77.4 & 12.9 & 21.4 \\
\hline 18 & $19 M$ & 65.8 & 11.0 & 21.4 \\
\hline Mean \pm SD & & $68.5 \pm 8.5$ & $11.4 \pm 1.4$ & $21.7 \pm 2.4$ \\
\hline
\end{tabular}

$\mathrm{MRI}$ - magnetic resonance images; $\mathrm{M}$ - male; $\mathrm{F}$ - female; $\mathrm{SD}$ - standard deviation; ${ }^{*}$ Area of the vessel-candidates in the $20 \times 30 \mathrm{~mm}$ rectangle $\left(600 \mathrm{~mm}^{2}\right) ;{ }^{* *}$ Maximum thickness of the retrodiscal tissue

trast to the small variations evident in young adults. Notably, normalised vascular density was lower in adults than in foetuses. Although our identification of vessel candidates using MRI did not provide absolute values, this study, likely representing the first attempt at quantitative evaluation, suggested that evaluation of inter-individual variations would be feasible. For example, although $>5$-fold variations were observed in foetuses, it is not clear if these differences would be reduced postnatally. Notably, in foetuses as well as in adults, the thickness (anteroposterior length) of the retrodiscal tissue did not correlate with vascular sectional area. Therefore, whether the vascular content in any individual is rich or poor may not depend on size, but may be determined genetically.

Sano [21] suggest that the retrodiscal tissue may have the so-called "blood-pumping function": as the condyle moves forward, elastic tissues in the deeper layer expand the inner space of the plexus, increasing its blood supply [10]. The vascular con-
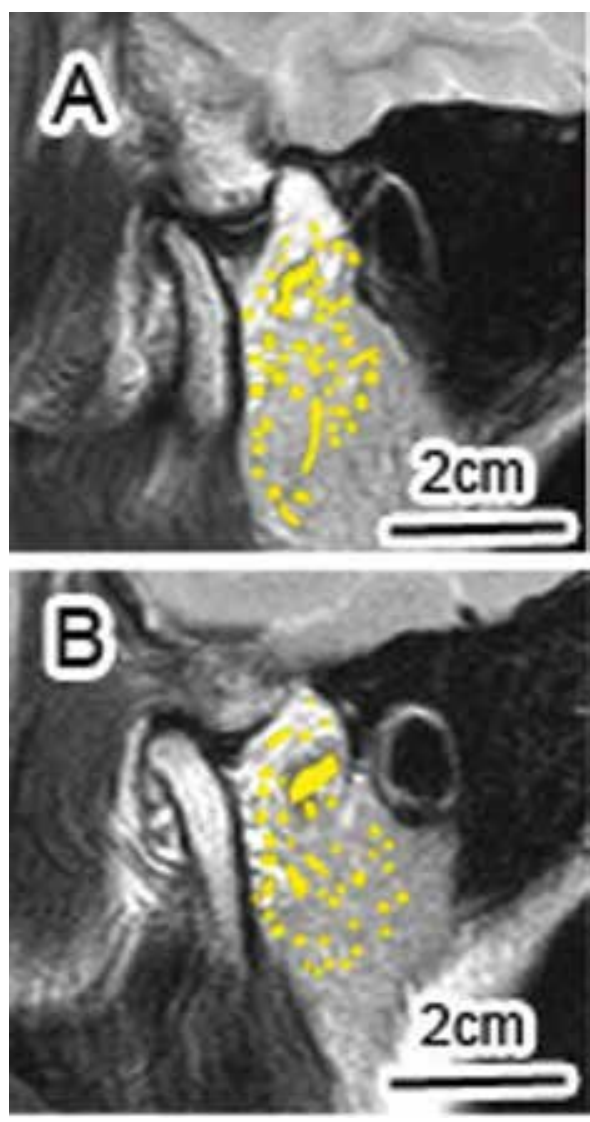

Figure 4. Individual variation in amount of vessel-candidates in the young adult retrodiscal tissue: T2-weighted magnetic resonance images (MRI). Yellow colours indicate vessel candidates in the MRI. Panel A (case 6 in Table 2; 21 years old female) and panel $\mathbf{B}$ (case 11 in Table 2; 25 years old female) display the sagittal plane that contained largest or smallest amount of vessel-candidates, respectively.

tent of retrodiscal tissue has been a major focus of interest to dental radiologists, but always in relation to TMJ pain or dislocation $[2,6,7,13,22,24,25]$. Lee and Yoon [14] demonstrated that the relative signal intensity of retrodiscal tissue in MRI was significantly correlated with joint pathology, including osteoarthritis, effusion, dislocation and pain. Higher T2 signal intensity, due to a richer vascular supply, has been observed in the retrodiscal tissue of painful compared to painless TMJs [2, 22, 25]. Moreover, Kober et al. [12] and Ohkubo et al. [17] compared the open- and closed-mouth positions, and found that the former was better for showing the vascular content of the retrodiscal tissue. In the present study, inter-individual differences in vascular content, as shown by MR imaging, did not appear to be significant in normal young adults. 


\section{CONCLUSIONS}

These findings suggest that the considerable inter-individual difference evident in the vascular content of foetal retrodiscal tissue may be reduced during further development.

\section{ACKNOWLEDGEMENTS}

This research was supported by Oral Health Science Centre Grant hrc8 from Tokyo Dental College, and by a Project for Private Universities matching fund subsidy from MEXT (Ministry of Education, Culture, Sports, Science and Technology), Japan, 2010-2012.

\section{REFERENCES}

1. Alkofide EA, Clark E, el-Bermani W, Kronman JH, Mehta N (1997) The incidence and nature of fibrous continuity between the sphenomandibular ligament and the anterior malleolar ligament of the middle ear. J Orofac Pain, 11: 7-14.

2. Chiba M, Kumagai M, Echigo S (2007) Association between high signal intensity in the posterior disc attachment seen on T2 weighted fat-suppressed images and temporomandibular joint pain. Dentomaxillofac Radiol, 36: 187-191.

3. Coleman RD (1970) Temporomandibular joint: relation of the retrodiscal zone to Meckel's cartilage and lateral pterygoid muscle. J Dent Res, 49: 626-630.

4. Harada Y, Ishizeki K (1998) Evidence for transformation of chondrocytes and site-specific resorption during the degeneration of Meckel's cartilage. Anat Embryol, 197: 439-450.

5. Harpman JA, Woollard HH (1938) The tendon of the lateral pterygoid muscle. J Anat, 73: 112-115.

6. Holmlund AB, Gynther GW, Reinholt FP (1992) Disk derangement and inflammatory changes in the posterior disk attachment of the temporomandibular joint. A histologic study. Oral Surg Oral Med Oral Pathol, 73: 9-12.

7. Isberg A, Isacsson G, Johansson AS, Larson O (1986) Hyperplastic soft-tissue formation in the temporomandibular joint associated with internal derangement. A radiographic and histologic study. Oral Surg Oral Med Oral Pathol, 61: 32-38.

8. Katori $\mathrm{Y}$, Kawase T, Cho KH, Abe H, Rodríguez-Vázquez JF, Murakami G, Abe S (2012) Prestyloid compartment of the parapharyngeal space: a histological study using late-stage human fetuses. Surg Radiol Anat, 34: 909-920.

9. Katori Y, Kawase T, Cho KH, Abe H, Rodríguez-Vázquez JF, Murakami G, Fujimiya M (2013) Suprahyoid neck fascial configuration especially in the posterior compartment of the parapharyngeal space: a histological study using late-stage human fetuses. Clin Anat, 26:204-212

10. Kino K, Ohmura Y, Amagasa T (1993) Reconsideration of the bilaminar zone in the retrodiskal area of the temporomandibular joint. Oral Surg Oral Med Oral Pathol, 75: 410-421.

11. Kinoshita $H$, Umezawa $T$, Omine $Y$, Kasahara $M$, Rodríguez-Vázquez JF, Murakami G, Abe S (2013) Distribution of elastic fibers in the head and neck: a histological study using late-stage human fetuses. Anat Cell Biol, 46: 39-48.
12. Kober $C$, Hayakawa Y, Kinzinger G, Gallo L, Otonari-Yamamoto M, Sano T, Sader RA (2007) 3D-visualization of the temporomandibular joint with focus on the articular disc based on clinical T1-, T2-, and proton density weighted MR images. Int J CARS, 2: 203-210.

13. Kurita K, Westesson PL, Sternby NH, Eriksson L, Carlsson LE, Lundh H, Toremalm NG (1989) Histologic features of the temporomandibular joint disc and posterior disk attachment: comparison of symptom-free persons with normally potitioned disks and patients with internal degeneration. Oral Surg Oral Med Oral Pathol, 67: 635-643.

14. Lee SH, Yoon HJ (2009) The relationship between MRI findings and the relative signal intensity of retrodiscal tossue in patients with temporomandibular joint disorders. Oral Surg Oral Med Oral Pathol Oral Radiol Endod, 107: 113-115.

15. Mérida-Velasco JR, Rodríguez-Vázquez JF, Mérida-Velasco JA, Jimémenez-Collado J (1999) The vascular relationship between the temporomandibular joint and the middle ear in the human fetus. J Oral Maxillofac Surg, 57: 146-153.

16. Öğútcen-Toller M, Juniper RP (1993) The embryologic development of the human lateral pterygoid muscle and its relationships with the temporomandibular joint disc and Meckel's cartilage. J Oral Maxillofac Surg, 51: 772-778.

17. Ohkubo $M$, Sano $T$, Otonari-Yamamoto $M$, Hayakawa $Y$, Okano T, Sakurai K, Sato T, Sugiyama T, Ishida R (2009) Magnetic resonance signal intensity from retrodiscal tissue related to joint effusion status and disk displacement in elderly patients with temporomandibular joint disorders. Bull Tokyo Dent Coll, 50: 55-62.

18. Rees LA (1954) The structure and function of the mandibular joint. Br Dent J, 96: 125-133.

19. Rodríguez-Vázquez JF, Mérida-Velasco JR, Mérida-Velasco JA, Jiménez-Collado J (1998) Anatomical considerations on the discomalleolar ligament. J Anat, 192: 617-621.

20. Sakuma K, Sano T, Yamamoto M, Tachikawa T, Okano T (2003) Does decreased T1 signal intensity in the retrodiscal tissue of the temporomandibular joint reflects increased density of collagen fibers? Dentomaxillofac Radiol, 32: 222-228.

21. Sano T (2000) Recent developments in understanding temporomandibular joint disorders. Part 2: Changes in the retrodiscal tissue. Dentomaxillofac Radiol, 29: 260-263.

22. Suenaga S, Hamamoto S, Kawano K, Higashida Y, Noikura T (1996) Dynamic MR imaging of the temporomandibular joint in patients with arthrosis: relationship between contrast enhancement of the posterior disk attachment and joint pain. Am J Roentogenol, 166: 1475-1481.

23. Takahashi I, Mizoguchi I, Nakamura M, Kagayama M, Mitami H (1995) Effects of lateral pterygoid muscle hyperactivity on differentiation of mandibular condyles in rats. Anat Rec, 241: 328-336.

24. Takebayashi S, Takama T, Okada S, Masuda G, Matsubara S (1997) MRI of the TMJ disc with intravenous administration of gadopentetate dimeglumine. J Comput Assist Tomogr, 21: 209-215.

25. Tasali N, Cubuk R, Aricak M, Ozarar M, Saydam B, Nur H, Tuncbilek N (2012) Temporomandibular joint (TMJ) pain revisited with dynamic contrast-enhanced magnetic resonance imaging (DCE-MRI). Eur J Radiol, 81: 603-608.

26. Tomas X, Pomes J, Berenuer J, Mercader JM, Pons F, Danoso L (2007) Temporomandibular joint soft-tissue pathology, II: Nondisc abnormalities. Semin Ultrasound CT MR, 28: 205-212. 